\title{
Endoscopic Ultrasonography Findings of Early and Suspected Early Chronic Pancreatitis
}

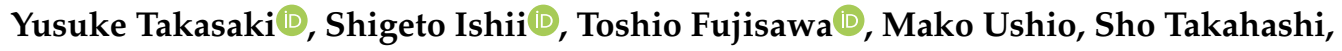 \\ Wataru Yamagata, Koichi Ito, Akinori Suzuki, Kazushige Ochiai, Ko Tomishima, Hiroaki Saito \\ and Hiroyuki Isayama *
}

Department of Gastroenterology, University of Juntendo, Tokyo 113-8421, Japan; ytakasa@juntendo.ac.jp (Y.T.); sishii@juntendo.ac.jp (S.I.); t-fujisawa@juntendo.ac.jp (T.F.); m-ushio@juntendo.ac.jp (M.U.); sho-takahashi@juntendo.ac.jp (S.T.); w.yamagata.mx@juntendo.ac.jp (W.Y.); kitoh@juntendo.ac.jp (K.I.); suzukia@juntendo.ac.jp (A.S.); k.ochiai.qd@juntendo.ac.jp (K.O.); tomishim@juntendo.ac.jp (K.T.); hiloaki@juntendo.ac.jp (H.S.)

* Correspondence: h-isayama@juntendo.ac.jp

Received: 14 October 2020; Accepted: 24 November 2020; Published: 27 November 2020

\begin{abstract}
Chronic pancreatitis $(\mathrm{CP})$ is associated with a risk of pancreatic cancer and is characterized by irreversible morphological changes, fibrosis, calcification, and exocrine and endocrine insufficiency. $\mathrm{CP}$ is a progressive disease with a poor prognosis and is typically diagnosed at an advanced stage. The Japan Pancreas Society proposed criteria for early CP in 2009, and their usefulness has been reported. Recently, a mechanism definition was proposed by the International Consensus Guidelines and early $\mathrm{CP}$ was defined as a disease state that is not based on disease duration. $\mathrm{CP}$ is diagnosed by computed tomography, magnetic resonance imaging, and endoscopic cholangiopancreatography, which can detect calcification and dilation of the pancreatic ducts; however, detecting early $\mathrm{CP}$ with these modalities is difficult because subtle changes in early $\mathrm{CP}$ occur before established $\mathrm{CP}$ or end-stage CP. Endoscopic ultrasonography (EUS) is useful in the diagnosis of early CP because it allows high-resolution, close-up observation of the pancreas. In addition to imaging findings, EUS with elastography enables measurement of the stiffness of the pancreas, an objective diagnostic measure. Understanding the EUS findings of early CP is important because a histological diagnosis is problematic, and other modalities are not capable of detecting subtle changes in early $\mathrm{CP}$.
\end{abstract}

Keywords: early CP; EUS; rosemont criteria

\section{Introduction}

Chronic pancreatitis $(\mathrm{CP})$ causes irreversible changes such as parenchymal atrophy, fibrosis, and calcification. The complications of advanced $\mathrm{CP}$ include severe chronic pain and exocrine/endocrine insufficiency. Patients typically describe their pain as a dull, sharp or nagging sensation in the upper abdomen, which can radiate to the back, and often presents after, or is worsened by food intake [1,2]. Exocrine insufficiency causes symptoms such as bloating, steatorrhea and diarrhea, and requires appropriate dosage of pancreatic enzyme replacement therapy and monitoring for osteoporosis. Endocrine dysfunction often requires insulin replacement therapy and collaboration with a diabetes physician. These symptoms impair the quality of life [3]. Additionally, the incidence of pancreatic cancer is elevated in patients with CP. The standardized incidence of pancreatic cancer, adjusted for morbidity, age, and sex is 13.3-26.7 among patients with CP [4,5], and the hazard ratio for death from pancreatic cancer is 6.9 [6]. However, a definitive diagnosis of CP is typically only possible too late in the disease course to initiate treatments that might limit progression and/or minimize complications. To avoid advanced-stage complications and improve clinical outcomes, early diagnosis 
and treatment are essential before CP becomes established and irreversible [7]. Diagnosis of early CP is clinically challenging due to the lack of sensitive and specific methods or a gold standard technique. $\mathrm{CP}$ is diagnosed by the presence of stones in the pancreatic ducts or calcifications throughout the pancreas by computed tomography $(\mathrm{CT}), \mathrm{X}$-ray, or abdominal ultrasonography (AUS). It can also be diagnosed by irregular dilatation of the main pancreatic duct and irregular dilatation of pancreatic duct branches with variable intensity and a scattered distribution via endoscopic cholangiopancreatography (ERCP) and magnetic resonance cholangiopancreatography (MRCP). The Cambridge classification [8] incorporated CT, AUS and ERCP features to classify and grade disease severity. These diagnostic modalities accurately identify patients without pancreatic pathologic conditions and those with severe CP. However, the Cambridge classification provided poor diagnostic accuracy in evaluation of patients with equivocal or early CP. Such definitive image findings are absent in early CP, which cannot be diagnosed by those modalities. Endoscopic ultrasonography (EUS) enables detailed examination and scoring of the pancreatic parenchyma and duct because of its high resolution, close-up observation of the pancreas $[9,10]$. Therefore, EUS may be able to identify subtle changes in patients indicating early CP [11]. Severity, as observed using EUS, is classified based on the number of positive findings, and advanced CP with calcification can be classified as mild depending on the number of findings. This could result in a discrepancy between clinical progression and the EUS severity classification [12]. Therefore, EUS-based diagnostic criteria for CP were determined by expert consensus and based on the available evidence. The Rosemont criteria (RC) were published in 2009 [13] (Table 1).

Table 1. The Rosemont classification.

\begin{tabular}{c}
$\frac{\text { Parenchymal Criteria }}{\text { Major A }}$ \\
\hline Hyperechoic foci ( $>2$ mm in length/width with shadowing) \\
\hline Major B \\
\hline Lobularity ( $\geq 3$ contiguous lobules = “with honeycombing”) \\
\hline Minor \\
\hline Hyperechoic strands ( $\geq 3$ mm in at least 2 different directions with respect to the imaged plane) \\
\hline Hyperechoic foci ( $>2$ mm in length/width with no shadowing) Lobularity (noncontiguous \\
lobules = “without honeycombing”) \\
\hline Duct Criteria \\
\hline Major A \\
\hline MPD calculi (echogenic structure(s) within the MPD with acoustic shadowing) \\
\hline Minor \\
\hline Eilated side branches ( $>3$ tubular anechoic structures each measuring $\geq 1$ mm in width, budding from \\
the MPD)
\end{tabular}

The RC categorizes EUS findings as major A, major B, and minor, such that diagnosis is not only based on the number of positive findings. The major RC are hyperechoic foci with shadowing, main pancreatic duct (MPD) calculi, and lobularity with honeycombing. The minor criteria comprise cysts, strands, non-shadowing hyperechoic foci, lobularity without honeycombing, an MPD dilated $>3.5 \mathrm{~mm}$, irregular MPD contour, side branches dilated $>1 \mathrm{~mm}$, and a hyperechoic MPD margin. According to the $\mathrm{RC}$, each case is classified as consistent with $\mathrm{CP}$, suggestive of $\mathrm{CP}$, indeterminate for 
$\mathrm{CP}$, or normal. The RC do not encompass early $\mathrm{CP}$, but EUS findings-as described in the RC-have been used to investigate early CP. The ability of EUS to diagnose early CP has been evaluated [14-19]. However, accurate diagnosis of early $\mathrm{CP}$ is not possible using imaging criteria alone. EUS also enables indirect assessment of pancreatic exocrine insufficiency [20] and is useful for indicating treatment for both $\mathrm{CP}$ and early $\mathrm{CP}$.

\section{Materials and Methods}

\subsection{EUS Findings of Early CP}

According to EUS, normal pancreatic parenchyma has similar or slightly higher echogenicity than the liver and exhibits a fine reticulate pattern [21]. Although few papers have defined imaging findings for early $\mathrm{CP}$, the Japan Pancreas Society (JPS) proposed imaging findings for early $\mathrm{CP}$ based on RC. The EUS findings of early CP are of the minor and major B categories of the RC. However, hyperechoic foci with shadowing, MPD dilation, and irregular MPD contour are excluded because these findings are seen in established or end-stage $\mathrm{CP}$. The histopathological changes reflected by the EUS findings of early $\mathrm{CP}$ are unclear due to the paucity of surgical studies and the scarcity of EUS-guided fine-needle aspiration specimens, which hampers evaluation. Histologic correlations among the EUS findings for RC were obtained for cyst, hyperechoic ductal margins, and dilated side branches. A cyst is considered to represent a pseudocyst or retention cyst, hyperechoic ductal margin to indicate fibrosis of the pancreatic duct, and dilated side branches to represent side-branch ectasia. Albshir et al. [22] reported that the number of preoperative EUS findings was significantly correlated with the number of fibrosis findings in surgical specimens. Varadarajulu et al. [23] performed a prospective study of the correlations between EUS criteria as they pertain to non-calcific $C P$ and the histology results of surgical specimens. The preoperative EUS findings were significantly associated with those of resected pancreatic tissue. These reports suggest that EUS findings can be associated with fibrosis of the pancreatic parenchyma.

\section{Lobularity (Figure 1a)}

Lobularity is defined endosonographically as a reticulated area surrounded by $\geq 5 \mathrm{~mm}$ structures with rims that are hyperechoic relative to the echogenicity in the central areas. At least three lobules in the body or tail are necessary for the feature to be considered present. If at least three of the lobules are contiguous, the feature is termed "lobularity with honeycomb" according to the $\mathrm{RC}$, a major B criterion. If lobules are non-contiguous, the feature is termed "lobularity without honeycomb", a minor RC. Lobularity with honeycomb is considered to indicate stronger $\mathrm{CP}$ changes than lobularity without honeycomb, but the 2019 JPS criteria make no such distinction. Lobularity should be assessed only within the pancreatic body and tail because this finding is relatively common in the pancreatic head, especially the ventral pancreatic area.

2. Hyperechoic foci without shadowing (Figure 1b)

Hyperechoic foci with post-acoustic shadowing indicate intraparenchymal calcification and are indicative of a major A on the RC. This finding is considered as established CP. Hyperechoic foci without shadowing are defined as echogenic structures $\geq 3 \mathrm{~mm}$ in length and width with no shadowing. This finding is classified as minor according to the RC. At least three of these structures are needed for the feature to be considered abnormal. Hyperechoic foci without shadowing are indicative of focal fibrosis.

\section{Strands (Figure 1c)}

Strands are defined as hyperechoic lines $\geq 3 \mathrm{~mm}$ in length in at least two directions with respect to the imaged plane. At least three of these structures are needed for the feature to be considered abnormal. This finding is indicative of bridging fibrosis. 
4. Hyperechoic MPD margin (Figure 1d)

A hyperechoic MPD margin is defined as an echogenic, distinct structure accounting for $>50 \%$ of the entire MPD in the pancreatic body and tail. Evaluation is subjective because it is difficult to assess the pancreatic ducts along the long axis of linear-type EUS. This finding is indicative of a thickened pancreatic duct wall [12].

5. Dilated side branches (Figure 1e)

Dilated side branches are defined as three or more tubular echoic structures each $\geq 1 \mathrm{~mm}$ in width and budding from the MPD. This finding is thought to be caused by narrowing of the branches due to micro-fibrosis.

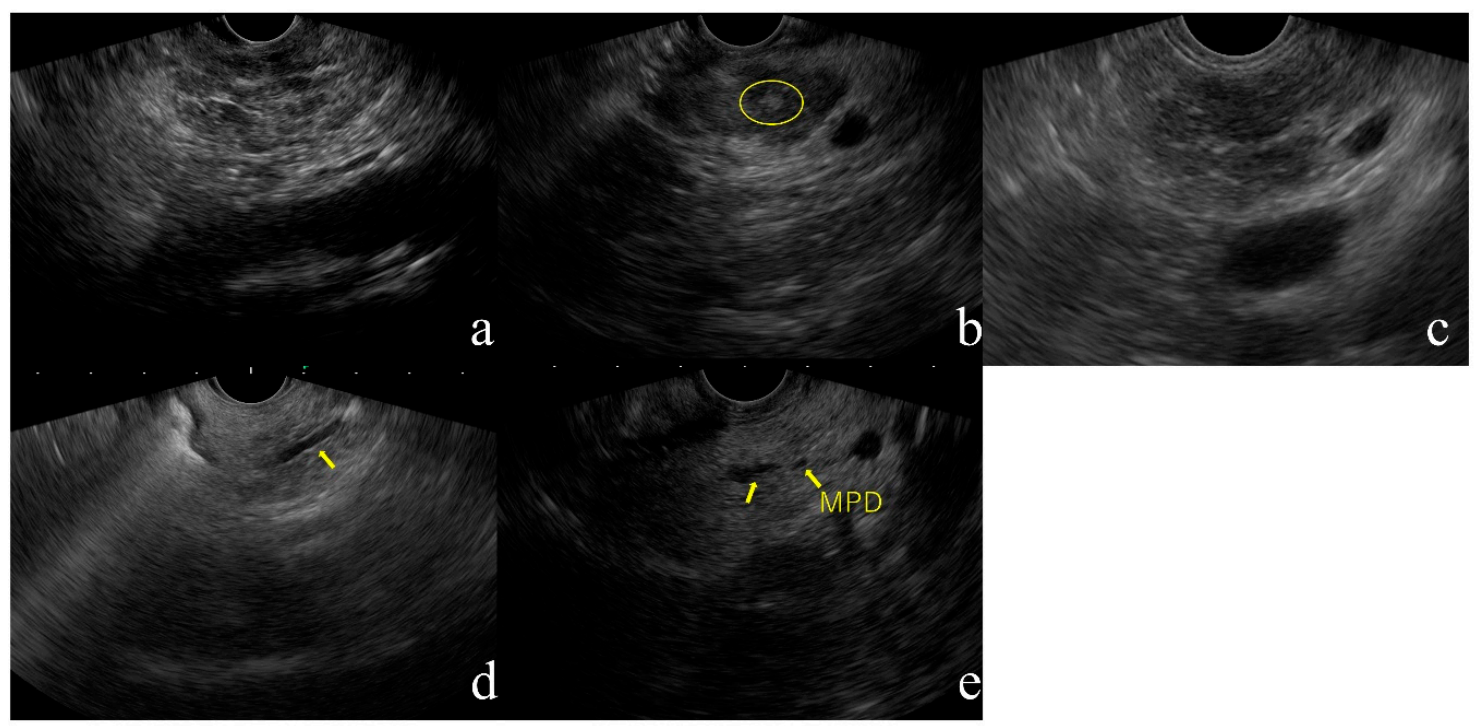

Figure 1. Diagnostic flowchart of CP in JPS guideline 2019. Abbreviations, CP, chronic pancreatitis; JPS, Japan Pancreas Society. (a) Lobularity, (b) Hyperechoic foci without shadowing, (c) Strands, (d) Hyperechoic MPD margin, (e) Dilated side branches

It is difficult to determine whether the above findings are indicative of early $\mathrm{CP}$ or changes due to aging. A study on the association between EUS findings of $\mathrm{CP}$ and age reported a trend in which abnormal EUS findings increase with age in patients over 60 years of age [24]. Whether these findings are indicative of early $\mathrm{CP}$ or aging changes should be determined clinically.

\subsection{Definition and Assessment of Early CP}

The term early stage CP was first used by Ammann et al. in 1996 [25]. They argued that the definition of alcoholic early CP should be independent of histological findings such as those from long-term follow-up that would eventually reveal the typical clinical features of CP [25]. Before using early stage $\mathrm{CP}$, the majority of classification systems and consensus guidelines applied the term probable $\mathrm{CP}$ for cases with a high likelihood of $\mathrm{CP}$ but that did not meet the imaging criteria for definite $\mathrm{CP}$. The American Pancreatic Association (APA) published practice guidelines for CP in 2014 [26]. These guidelines suggested classification of $\mathrm{CP}$ based on imaging or histological findings, but early $\mathrm{CP}$ could not be defined due to insufficient evidence. The United European Gastroenterology evidence-based guidelines for the diagnosis and therapy of CP were published in 2017 [27]. These guidelines suggested classification of $\mathrm{CP}$ based on imaging or histological findings, but early $\mathrm{CP}$ could not be defined due to insufficient evidence. The United European Gastroenterology evidence-based guidelines for the diagnosis and therapy of CP were published in 2017 [20]. In 2016, The International Consensus Guidelines on CP (formulated by the International Association of Pancreatology, APA, 
JPS, and European Pancreatic Club) were proposed [28]. Those consensus guidelines were based on the mechanistic definitions " $\mathrm{CP}$ is a pathologic fibro-inflammatory syndrome of the pancreas in individuals with genetic, environmental and/or other risk factors who develop persistent pathologic responses to parenchymal injury or stress" and "common features of established and advanced CP included pancreatic atrophy, fibrosis, pain syndromes, duct distortion and strictures, calcifications, pancreatic exocrine dysfunction, pancreatic endocrine dysfunction and dysplasia [28]. The mechanistic definitions offer a potential solution to the problem of defining and diagnosing early $\mathrm{CP}$ and provide a framework for diagnostic criteria by considering risk factors, biomarkers of inflammation, pain, and functional status within the clinical context. The consensus guidelines adopt the progressive model of $\mathrm{CP}$ consisting of five disease stages: at risk, acute pancreatitis (AP)—recurrent AP, early $\mathrm{CP}$, established $\mathrm{CP}$, and end-stage $\mathrm{CP}$. A recent international consensus on early $\mathrm{CP}$ failed to agree on diagnostic criteria [29]. However, a consensus was achieved on defining "early" as a disease state that is not based on disease duration, because early CP cannot be diagnosed by imaging modalities alone. Although no international consensus was reached, the concept of early $\mathrm{CP}$ is very important. Because an understanding of $\mathrm{CP}$ based on the mechanism definition is a fundamental concept and an enhanced understanding of $\mathrm{CP}$ imaging findings, particularly those of EUS, is required. There is a need to decide on a definition of early $\mathrm{CP}$ that allows us to reach an international consensus.

\subsection{Japanese Diagnostic Criteria for Early CP}

In 2009, the first diagnostic criteria for early CP were proposed by the JPS [7]. Early CP was defined as the absence of $\mathrm{CP}$ findings and the presence of at least two of the four clinical and imaging findings of early CP upon EUS or ERCP. Based on the RC [13], the EUS findings of early CP are as follows (five parenchymal and two ductal features): (1) lobularity with honeycombing, (2) lobularity without honeycombing, (3) hyperechoic foci without shadowing, (4) stranding, (5) cysts, (6) dilated side branches, and (7) hyperechoic MPD. More than two of the seven features are sufficient for the diagnosis of early CP. Among 83 patients diagnosed with early CP using the JPS criteria and who completed a 2-year follow-up, four (4.8\%) progressed to defined CP. All four patients were male, had a history of drinking alcohol and smoking, and continued to drink alcohol. By contrast, 31 patients (37.3\%) were downgraded [30]. Additionally, Hashimoto et al. [31] reported that epigastric pain syndrome and pancreatic enzyme abnormalities were associated with early CP in JPS criteria. Yamawaki et al. [32] reported that Camostat Mesilate, Pancrelipase, and Rabeprazole combination therapy improved the epigastric pain associated with early CP. Thus, the JPS criteria can be used to identify early CP. However, in some patients, the EUS findings improved without treatment. Sheel et al. [33] followed up 66 patients previously diagnosed with CP by EUS. Over a median of 3 years of follow-up, one-third of the patients with EUS features of early $\mathrm{CP}$ progressed to definite $\mathrm{CP}$. This suggests that the EUS imaging criteria have low specificity. Therefore, the JPS CP criteria were revised in 2019 to increase their diagnostic specificity [34]. The 2019 CP criteria included two additional factors-genetic mutations and history of acute pancreatitis-and a revised definition of continuous heavy alcohol drinking as $\geq 60 \mathrm{~g} /$ day of pure ethanol to be consistent with conditions of alcoholic liver injury. New diagnostic criteria for pancreatitis-related genetic abnormalities and history of acute pancreatitis have been added to the diagnostic criteria, with emphasis on assessment of risk factors based on the mechanism definition. Recently, SPINK1 and PRSS gene abnormalities have been reported to be associated with hereditary pancreatitis or idiopathic CP [35-40], and these two gene abnormalities have been added to the list of items in this revision. The JPS 2019 CP criteria comprise seven items: (1) characteristic imaging findings, (2) characteristic histological findings, (3) repeated upper abdominal pain, (4) abnormal pancreatic enzyme levels in the serum or urine, (5) abnormal pancreatic exocrine function, and (6) continuous heavy drinking of alcohol equivalent to or more than $60 \mathrm{~g} /$ day of pure ethanol or a genetic mutation (PRSS1 or SPINK1), and (7) history of acute pancreatitis (Table 2). 
Table 2. Clinical diagnostic criteria for CP in 2019 by JPS.

\section{Diagnostic Items for $\mathrm{CP}$}

(1) Characteristic imaging findings

(2) Characteristic histological findings

(3) Repeated upper abdominal pain

(4) Abnormal pancreatic enzyme levels in the serum or urine

(5) Abnormal pancreatic exocrine function

(6) Continuous heavy drinking of alcohol equivalent to $60 \mathrm{~g} /$ day of pure ethanol or genetic mutation (PRSS1 or SPINK1)

(7) History of acute pancreatitis

Definite CP: either a or b

a. Definite findings of (1) or (2)

b. Probable findings of (1) or (2), plus more than two items among (3), (4), and (5)

Probable CP

Probable findings of (1) or (2)

Early CP

More than three items among (3)-(7) plus image findings of early $\mathrm{CP}$

JPS, the Japan Pancreas Society; CP, chronic pancreatitis.

The characteristic imaging findings have also been revised. MRCP can be used for initial screening because of recent improvements in its resolution. Ito et al. [41] reported that irregular dilatation of three branches on MRCP was more often observed in early CP, defined by JPS criteria 2009, compared to non-early $\mathrm{CP}$. The EUS findings were revised to be simpler because of problems with inter-observer agreement rates [42-44]. The EUS findings are as follows: (1) hyperechoic foci (non-shadowing) or strands, (2) lobularity, (3) hyperechoic MPD margin, and (4) dilated side branches. At least two of the four EUS findings, including (1) or (2), are required for the diagnosis of early CP. The presence of cysts was excluded because it can be difficult to distinguish pancreatic cysts such as intraductal papillary mucinous neoplasm. A diagnostic flowchart for CP created by the author based on the 2019 JPS CP criteria is shown in Figure 2.

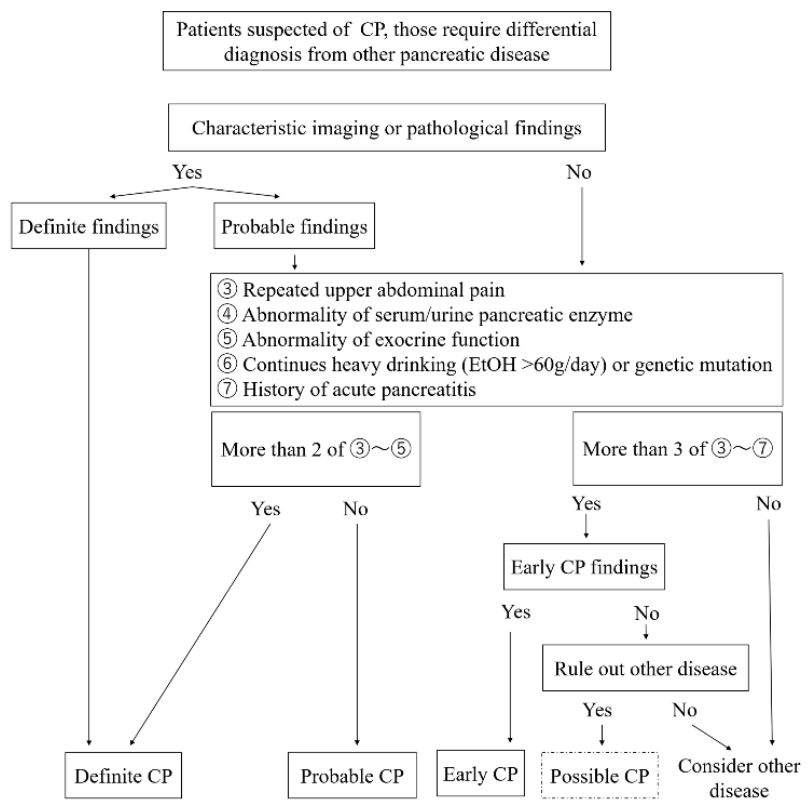

Figure 2. Endoscopic ultrasonography (EUS) images of the CP based on JPS guideline. 


\subsection{Limitations of the Diagnostic Criteria for Early CP}

The JPS criteria were the first to refer to the diagnosis of early $\mathrm{CP}$, and it is expected that revision will further increase their accuracy. However, an international consensus definition of early $\mathrm{CP}$ has yet to be reached due to several limitations. Some patients diagnosed with early $\mathrm{CP}$ progress to $\mathrm{CP}$ and others do not. This may be due to the low accuracy of the diagnostic criteria for early $\mathrm{CP}$. Another problem is the low inter-observer agreement rate of EUS findings for CP. Koh et al. [44] reported a multicenter validation study in Asia. In this study, the inter-observer agreement rates were determined for "Hyperechoic foci with shadowing", "Non-shadowing hyperechoic foci", "Strands", "Lobularity with non-contiguous lobules", "Lobularity with honeycombing", "Cysts", "Dilated main pancreatic duct", "Irregular pancreatic duct", "Hyperechoic duct wall", "Dilated side branches", "Calculi in the main pancreatic duct". Cysts and the calculi in the main pancreatic duct had a kappa $>0.8$, five factors (hyperechoic foci with shadowing, lobularity with honeycombing, dilated main pancreatic duct, irregular pancreatic duct, dilated side branches) had a kappa of 0.6-0.8, and four factors (non-shadowing hyperechoic foci, strands, lobularity with non-contiguous lobules, hyperechoic duct wall) had a kappa $<0.6$. Diagnostic criteria consist of clinical, hematological, and imaging findings. Some patients may meet some, but not all, of the diagnostic criteria, and those are classified as suspected early CP. The concept of early CP or suspected early CP is shown in Figure 3.

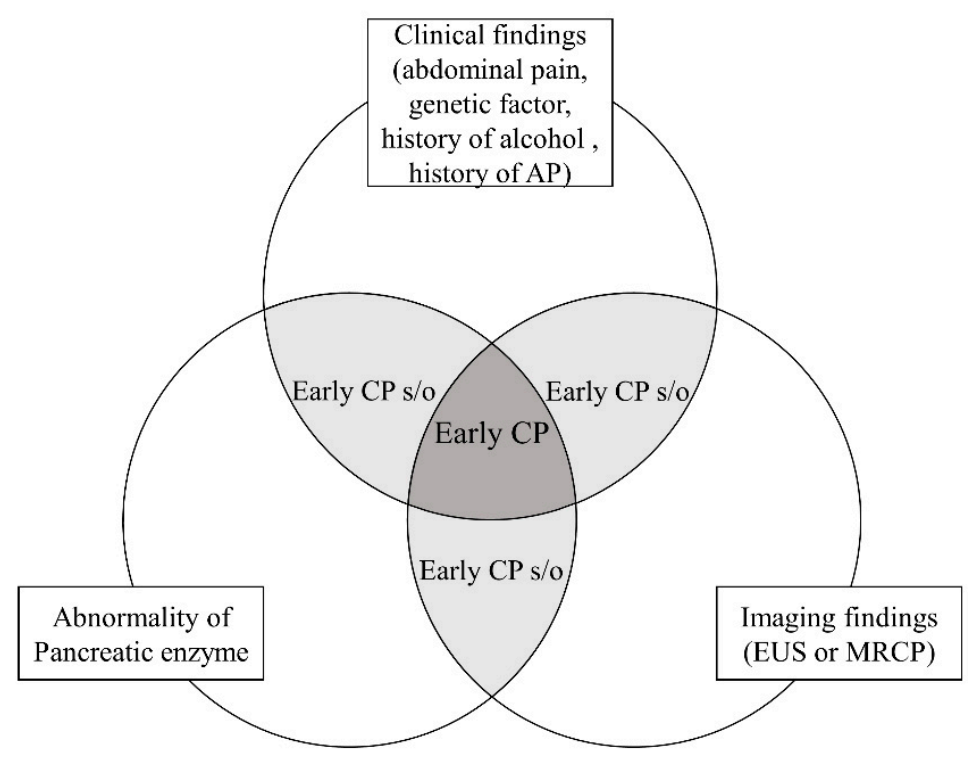

Figure 3. The concept of early CP.

The natural history of early $\mathrm{CP}$ and whether it requires for treatment are unclear, and so further research is needed. Genetic factors are also important in patients with $\mathrm{CP}$. However, evidence for a genetic factor in early $\mathrm{CP}$ is lacking. In addition, genetic and complicated pancreatic exocrine function tests may not be performed in clinical practice. Additionally, patients with idiopathic CP may have not been adequately evaluated because of the disproportionately large weight assigned to continuous heavy alcohol drinking as a clinical/functional feature in the diagnostic criteria.

\subsection{EUS-Elastography}

EUS is the most sensitive imaging technique for the diagnosis of $\mathrm{CP}$, mainly during the early stages. However, objective measures are required because of the potential for low inter-observer agreement. Elastography evaluates tissue hardness and is based on the principle that softer parts of tissues more readily deform under compression than harder parts. EUS-elastography enables the visualization of tissue stiffness, including that of the pancreatic parenchyma. There are two types of 
elastography: qualitative and semi-quantitative/quantitative [45]. Strain elastography is a qualitative method. This technique measures strain, which is negatively correlated with tissue hardness and allows the direct visualization of information reflecting strain as a strain distribution map (elastogram), which, for visualization purposes, is color-coded and displayed next to the conventional B-mode image on the screen. To improve the accuracy and reproducibility of the elastography and to reduce the human bias, semiquantitative/quantitative analysis of tissue stiffness has been used. Semi-quantitative elastography analysis include strain histogram (SH) and strain ratio (SR), and quantitative elastography analysis includes shear-wave elastography. EUS-strain elastography includes methods based on region of interest (ROI) coloration and image heterogeneity and measurement of the SR for image quantification. The value of EUS-strain elastography for the diagnosis of $\mathrm{CP}$ based on parenchymal stiffness [46] and pancreatic exocrine insufficiency $[47,48]$ has been discussed. Kim et al. reported a mean SR of $3.78 \pm 1.35$ for the normal pancreas and $8.21 \pm 5.16$ for $\mathrm{CP}$; the sensitivity, specificity, and accuracy of the SR for detecting CP using a cut-off value of 5.62 were $71.6 \%, 75.2 \%$, and $74.8 \%$, respectively [49]. The results of EUS-strain elastography are correlated with $\mathrm{CP}$ stage according to the RC [50]. EUS-strain elastography is expected to improve the accuracy of CP diagnosis but has several limitations. First, it is an operator-dependent procedure that does not measure an absolute hardness value. Second, EUS-strain elastography is affected by the size and/or position of the ROI. EUS-shear-wave elastography exhibits greater precision for CP cases because it measures the absolute hardness value of the pancreatic parenchyma [51,52]. An acoustic radiation force (push pulse) is sent to the focal point of the ROI, at the edge of which a shear wave is generated. The velocity of the shear wave between two search points is calculated with a tracking pulse. Yamashita et al. [53] reported that the diagnostic accuracy of EUS-shear-wave elastography for $\mathrm{CP}$ was 0.97 , and based on a cut off value of 2.19 , the modality exhibited $100 \%$ sensitivity and $94 \%$ specificity for the diagnosis of $\mathrm{CP}$. However, there was no difference between patients with indeterminate $\mathrm{CP}$ according to the RC (which is considered equivalent to early $\mathrm{CP}$ ) and non-CP patients. The limitations of EUS-shear-wave elastography include the difficulty in evaluating a single location in the pancreas, its usage difficulty in obese patients, and instability caused by breathing. The usefulness of EUS-elastography for the diagnosis of early CP is unknown; therefore, further studies are needed. EUS-elastography, which is minimally invasive and enables quantitative evaluation, will facilitate the diagnosis of early CP.

\subsection{The Future of Diagnosis in Early CP}

Imaging diagnosis of early $\mathrm{CP}$ requires sensitive diagnostic modalities to capture subtle morphological changes such as fibrosis of the pancreatic parenchyma and dilation of the branch, therefore, EUS is considered to be the most suitable modality. Secretin-enhanced MRCP, contrast-enhanced AUS, and non-contrast spin-label MRI have been investigated as methods to evaluate the early CP. A recent study, which specified Magnetic resonance Imaging as a Non-Invasive Method for the Assessment of Pancreatic fibrosis (MINIMAP), was designed to incorporate both the parenchymal and ductal features of chronic pancreatitis [54]. These methods have the potential to be useful in the diagnosis of early $\mathrm{CP}$. The modalities for imaging of early $\mathrm{CP}$ required are minimally invasive, simple and sensitive. Furthermore, it is important to be able to diagnose early $\mathrm{CP}$ in a combination of diagnostic imaging and the development of laboratory tests, which can measure the decline of early endocrine and exocrine functions. Artificial intelligence (AI) is also useful for the diagnosis of early CP. In EUS, AI is used for detecting anatomical features, differential pancreatic tumors and cysts $[55,56]$. AI systems and deep learning based on neural networks, which is a machine learning technique that is widely used in the medical field, involves three phases. First, data are collected and annotated, second, the deep learning architecture is built and third, training and ability validation takes place. There is no consensus on the definition of early chronic pancreatitis, so AI is not yet needed, but it may solve the problem of interobserver agreement in the future. 


\section{Conclusions}

$\mathrm{CP}$ is not curable, and most patients will experience longstanding symptoms, such as bloating, steatorrhea and diarrhea, which detract from their quality of life. Patients with established CP or end-stage $\mathrm{CP}$ will likely eventually require treatment for abdominal pain, exocrine insufficiency with maldigestion, and endocrine insufficiency with diabetes. Treatment and lifestyle changes should be recommended to patients with early CP before their disease progresses. EUS is important for the diagnosis of early CP. Some findings can be detected only by EUS, and its combination with, for instance, elastography and contrast studies will further improve the accuracy of diagnosis of early $\mathrm{CP}$. The mechanistic definition proposed a concept of early $\mathrm{CP}$, which can exhibit the reversible structural fibrotic change of end stage CP. However, no international consensus has been reached on its definition. Further advances in imaging devices may reveal the pathogenesis of early $\mathrm{CP}$, just as EUS has gone from mechanical to electronic with increased resolution to provide more detailed information. Future technologies such as AI may also improve the accuracy of diagnosis of early CP. Such advances may lead to an international consensus, although the diagnosis of early $\mathrm{CP}$ is currently controversial.

Author Contributions: Writing—original draft preparation, Y.T.; writing—review and editing, H.I.; contributed editing the tables and manuscript, S.I., T.F., M.U., S.T., W.Y., K.I., A.S., K.O., K.T., H.S. All authors have read and agreed to the published version of the manuscript.

Funding: This research received no external funding.

Conflicts of Interest: The authors declare no conflict of interest.

\section{References}

1. Phillips, A.E.; Faghih, M.; Kuhlmann, L.; Larsen, I.M.; Drewes, A.M.; Singh, V.K.; Yadav, D.; Olesen, S.S.; Pancreatic Quantitative Sensory Testing (P-QST) Consortium. A clinically feasible method for the assessment and characterization of pain in patients with chronic pancreatitis. Pancreatology 2020, 20, 25-34. [CrossRef] [PubMed]

2. Drewes, A.M.; Bouwense, S.A.W.; Campbell, C.M.; Ceyhan, G.O.; Delhaye, M.; Demir, I.E.; Garg, P.K.; van Goor, H.; Halloran, C.; Isaji, S.; et al. Guidelines for the understanding and management of pain in chronic pancreatitis. Pancreatology 2017, 17, 720-731. [CrossRef]

3. Machicado, J.D.; Amann, S.T.; Anderson, M.A.; Abberbock, J.; Sherman, S.; Conwell, D.L.; Cote, G.A.; Singh, V.K.; Lewis, M.D.; Alkaade, S.; et al. Quality of Life in Chronic Pancreatitis is Determined by Constant Pain, Disability/Unemployment, Current Smoking, and Associated Co-Morbidities. Am. J. Gastroenterol. 2017, 112, 633-642. [CrossRef] [PubMed]

4. Talamini, G.; Falconi, M.; Bassi, C.; Sartori, N.; Salvia, R.; Caldiron, E.; Frulloni, L.; Di Francesco, V.; Vaona, B.; Bovo, P.; et al. Incidence of cancer in the course of chronic pancreatitis. Am. J. Gastroenterol. 1999, 94, 1253-1260. [CrossRef] [PubMed]

5. Malka, D.; Hammel, P.; Maire, F.; Rufat, P.; Madeira, I.; Pessione, F.; Levy, P.; Ruszniewski, P. Risk of pancreatic adenocarcinoma in chronic pancreatitis. Gut 2002, 51, 849-852. [CrossRef] [PubMed]

6. Bang, U.C.; Benfield, T.; Hyldstrup, L.; Bendtsen, F.; Beck Jensen, J.E. Mortality, cancer, and comorbidities associated with chronic pancreatitis: A Danish nationwide matched-cohort study. Gastroenterology 2014, 146, 989-994. [CrossRef] [PubMed]

7. Shimosegawa, T.; Kataoka, K.; Kamisawa, T.; Miyakawa, H.; Ohara, H.; Ito, T.; Naruse, S.; Sata, N.; Suda, K.; Hirota, M.; et al. The revised Japanese clinical diagnostic criteria for chronic pancreatitis. J. Gastroenterol. 2010, 45, 584-591. [CrossRef]

8. Axon, A.T.; Classen, M.; Cotton, P.B.; Cremer, M.; Freeny, P.C.; Lees, W.R. Pancreatography in chronic pancreatitis: International definitions. Gut 1984, 25, 1107-1112. [CrossRef]

9. Frokjaer, J.B.; Akisik, F.; Farooq, A.; Akpinar, B.; Dasyam, A.; Drewes, A.M.; Haldorsen, I.S.; Morana, G.; Neoptolemos, J.P.; Olesen, S.S.; et al. Guidelines for the Diagnostic Cross Sectional Imaging and Severity Scoring of Chronic Pancreatitis. Pancreatology 2018, 18, 764-773. [CrossRef]

10. Yoshida, T.; Yamashita, Y.; Kitano, M. Endoscopic Ultrasound for Early Diagnosis of Pancreatic Cancer. Diagnostics 2019, 9, 81. [CrossRef] 
11. Dominguez-Munoz, J.E.; Drewes, A.M.; Lindkvist, B.; Ewald, N.; Czakó, L.; Rosendahl, J.; Löhr, J.M.; Löhr, M.; Besselink, M.; Mayerle, J.; et al. Recommendations from the United European Gastroenterology evidence-based guidelines for the diagnosis and therapy of chronic pancreatitis. Pancreatology 2018, 18, 847-854. [CrossRef] [PubMed]

12. Raimondo, M.; Wallace, M.B. Diagnosis of early chronic pancreatitis by endoscopic ultrasound. Are we there yet? JOP 2004, 5, 1-7. [PubMed]

13. Catalano, M.F.; Sahai, A.; Levy, M.; Romagnuolo, J.; Wiersema, M.; Brugge, W.; Freeman, M.; Yamao, K.; Canto, M.; Hernandez, L.V. EUS-based criteria for the diagnosis of chronic pancreatitis: The Rosemont classification. Gastrointest. Endosc. 2009, 69, 1251-1261. [CrossRef]

14. Dancygier, H. Endoscopic ultrasonography in chronic pancreatitis. Gastrointest. Endosc. Clin. N. Am. 1995, 5, 795-804. [CrossRef]

15. Catalano, M.F.; Geenen, J.E. Diagnosis of chronic pancreatitis by endoscopic ultrasonography. Endoscopy 1998, 30 (Suppl. 1), A111-A115. [CrossRef]

16. Sahai, A.V.; Zimmerman, M.; Aabakken, L.; Tarnasky, P.R.; Cunningham, J.T.; van Velse, A.; Hawes, R.H.; Hoffman, B.J. Prospective assessment of the ability of endoscopic ultrasound to diagnose, exclude, or establish the severity of chronic pancreatitis found by endoscopic retrograde cholangiopancreatography. Gastrointest. Endosc. 1998, 48, 18-25. [CrossRef]

17. Catalano, M.F.; Lahoti, S.; Geenen, J.E.; Hogan, W.J. Prospective evaluation of endoscopic ultrasonography, endoscopic retrograde pancreatography, and secretin test in the diagnosis of chronic pancreatitis. Gastrointest. Endosc. 1998, 48, 11-17. [CrossRef]

18. Irisawa, A.; Mishra, G.; Hernandez, L.V.; Bhutani, M.S. Quantitative analysis of endosonographic parenchymal echogenicity in patients with chronic pancreatitis. J. Gastroenterol. Hepatol. 2004, 19, 1199-1205. [CrossRef] [PubMed]

19. Irisawa, A.; Katakura, K.; Ohira, H.; Sato, A.; Bhutani, M.S.; Hernandez, L.V.; Koizumi, M. Usefulness of endoscopic ultrasound to diagnose the severity of chronic pancreatitis. J. Gastroenterol. 2007, 42 (Suppl. 17), 90-94. [CrossRef]

20. Dominguez-Munoz, J.E.; Alvarez-Castro, A.; Larino-Noia, J.; Nieto, L.; Iglesias-Garcia, J. Endoscopic ultrasonography of the pancreas as an indirect method to predict pancreatic exocrine insufficiency in patients with chronic pancreatitis. Pancreas 2012, 41, 724-728. [CrossRef]

21. Sato, A.; Irisawa, A.; Bhutani, M.S.; Shibukawa, G.; Yamabe, A.; Fujisawa, M.; Igarashi, R.; Arakawa, N.; Yoshida, Y.; Abe, Y.; et al. Significance of normal appearance on endoscopic ultrasonography in the diagnosis of early chronic pancreatitis. Endosc. Ultrasound 2018, 7, 110-118. [CrossRef] [PubMed]

22. Albashir, S.; Bronner, M.P.; Parsi, M.A.; Walsh, R.M.; Stevens, T. Endoscopic ultrasound, secretin endoscopic pancreatic function test, and histology: Correlation in chronic pancreatitis. Am. J. Gastroenterol. 2010, 105, 2498-2503. [CrossRef] [PubMed]

23. Varadarajulu, S.; Eltoum, I.; Tamhane, A.; Eloubeidi, M.A. Histopathologic correlates of noncalcific chronic pancreatitis by EUS: A prospective tissue characterization study. Gastrointest. Endosc. 2007, 66, 501-509. [CrossRef] [PubMed]

24. Rajan, E.; Clain, J.E.; Levy, M.J.; Norton, I.D.; Wang, K.K.; Wiersema, M.J.; Vazquez-Sequeiros, E.; Nelson, B.J.; Jondal, M.L.; Kendall, R.K.; et al. Age-related changes in the pancreas identified by EUS: A prospective evaluation. Gastrointest. Endosc. 2005, 61, 401-406. [CrossRef]

25. Ammann, R.W.; Heitz, P.U.; Kloppel, G. Course of alcoholic chronic pancreatitis: A prospective clinicomorphological long-term study. Gastroenterology 1996, 111, 224-231. [CrossRef]

26. Conwell, D.L.; Lee, L.S.; Yadav, D.; Longnecker, D.S.; Miller, F.H.; Mortele, K.J.; Levy, M.J.; Kwon, R.; Lieb, J.G.; Stevens, T.; et al. American Pancreatic Association Practice Guidelines in Chronic Pancreatitis: Evidence-based report on diagnostic guidelines. Pancreas 2014, 43, 1143-1162. [CrossRef]

27. Lohr, J.M.; Dominguez-Munoz, E.; Rosendahl, J.; Besselink, M.; Mayerle, J.; Lerch, M.M.; Haas, S.; Akisik, F.; Kartalis, N.; Iglesias-Garcia, J.; et al. United European Gastroenterology evidence-based guidelines for the diagnosis and therapy of chronic pancreatitis (HaPanEU). United Eur. Gastroenterol. J. 2017, 5, 153-199. [CrossRef]

28. Whitcomb, D.C.; Frulloni, L.; Garg, P.; Greer, J.B.; Schneider, A.; Yadav, D.; Shimosegawa, T. Chronic pancreatitis: An international draft consensus proposal for a new mechanistic definition. Pancreatology 2016, 16, 218-224. [CrossRef] 
29. Whitcomb, D.C.; Shimosegawa, T.; Chari, S.T.; Forsmark, C.E.; Frulloni, L.; Garg, P.; Hegyi, P.; Hirooka, Y.; Irisawa, A.; Ishikawa, T.; et al. International consensus statements on early chronic Pancreatitis. Recommendations from the working group for the international consensus guidelines for chronic pancreatitis in collaboration with The International Association of Pancreatology, American Pancreatic Association, Japan Pancreas Society, PancreasFest Working Group and European Pancreatic Club. Pancreatology 2018. [CrossRef]

30. Masamune, A.; Nabeshima, T.; Kikuta, K.; Hamada, S.; Nakano, E.; Kume, K.; Kanno, A.; Sato, A.; Tachibana, Y.; Inatomi, O.; et al. Prospective study of early chronic pancreatitis diagnosed based on the Japanese diagnostic criteria. J. Gastroenterol. 2019, 54, 928-935. [CrossRef]

31. Hashimoto, S.; Futagami, S.; Yamawaki, H.; Kaneko, K.; Kodaka, Y.; Wakabayashi, M.; Sakasegawa, N.; Agawa, S.; Higuchi, K.; Akimoto, T.; et al. Epigastric pain syndrome accompanying pancreatic enzyme abnormalities was overlapped with early chronic pancreatitis using endosonography. J. Clin. Biochem. Nutr. 2017, 61, 140-145. [CrossRef] [PubMed]

32. Yamawaki, H.; Futagami, S.; Kaneko, K.; Agawa, S.; Higuchi, K.; Murakami, M.; Wakabayashi, M.; Sakasegawa, N.; Kodaka, Y.; Ueki, N.; et al. Camostat Mesilate, Pancrelipase, and Rabeprazole Combination Therapy Improves Epigastric Pain in Early Chronic Pancreatitis and Functional Dyspepsia with Pancreatic Enzyme Abnormalities. Digestion 2019, 99, 283-292. [CrossRef] [PubMed]

33. Sheel, A.R.G.; Baron, R.D.; Sarantitis, I.; Ramesh, J.; Ghaneh, P.; Raraty, M.G.T.; Yip, V.; Sutton, R.; Goulden, M.R.; Campbell, F.; et al. The diagnostic value of Rosemont and Japanese diagnostic criteria for 'indeterminate', 'suggestive', 'possible' and 'early' chronic pancreatitis. Pancreatology 2018, 18, 774-784. [CrossRef] [PubMed]

34. Masamune, A.; Irisawa, A.; Kikuda, K.; Ikeura, T.; Isaji, S.; Ishiguro, Y.; Itoi, T.; Ito, T.; Inui, K.; Ohara, H.; et al. Clinical Diagnostic Criteria for Chronic Pancreatitis 2019. Suizo 2019, 34, 279-281. (In Japanese) [CrossRef]

35. Zou, W.B.; Tang, X.Y.; Zhou, D.Z.; Qian, Y.Y.; Hu, L.H.; Yu, F.F.; Yu, D.; Wu, H.; Deng, S.J.; Lin, J.H.; et al. SPINK1, PRSS1, CTRC, and CFTR Genotypes Influence Disease Onset and Clinical Outcomes in Chronic Pancreatitis. Clin. Transl. Gastroenterol. 2018, 9, 204. [CrossRef]

36. Tang, X.Y.; Zou, W.B.; Yu, F.F.; Wang, L.; Ru, N.; Zhu, J.H.; Li, Z.S.; Liao, Z. Meta-analysis of the impact of the SPINK1 c.194+2T>C variant in chronic pancreatitis. Dig. Liver Dis. 2020, 52, 143-148. [CrossRef]

37. Sisman, G.; Tugcu, M.; Ayla, K.; Sebati, O.; Senturk, H. Mutation analysis of PRSS1, SPINK1 and CFTR gene in patients with alcoholic and idiopathic chronic pancreatitis: A single center study. Turk. J. Gastroenterol. 2015, 26, 176-180. [CrossRef]

38. Masamune, A.; Kikuta, K.; Hamada, S.; Nakano, E.; Kume, K.; Inui, A.; Shimizu, T.; Takeyama, Y.; Nio, M.; Shimosegawa, T. Nationwide survey of hereditary pancreatitis in Japan. J. Gastroenterol. 2018, 53, 152-160. [CrossRef]

39. Kumar, S.; Ooi, C.Y.; Werlin, S.; Abu-El-Haija, M.; Barth, B.; Bellin, M.D.; Durie, P.R.; Fishman, D.S.; Freedman, S.D.; Gariepy, C.; et al. Risk Factors Associated With Pediatric Acute Recurrent and Chronic Pancreatitis: Lessons From INSPPIRE. JAMA Pediatr. 2016, 170, 562-569. [CrossRef]

40. Giefer, M.J.; Lowe, M.E.; Werlin, S.L.; Zimmerman, B.; Wilschanski, M.; Troendle, D.; Schwarzenberg, S.J.; Pohl, J.F.; Palermo, J.; Ooi, C.Y.; et al. Early-Onset Acute Recurrent and Chronic Pancreatitis Is Associated with PRSS1 or CTRC Gene Mutations. J. Pediatr. 2017, 186, 95-100. [CrossRef]

41. Ito, T.; Ikeura, T.; Tanaka, T.; Mitsuyama, T.; Miyoshi, H.; Shimatani, M.; Uchida, K.; Takaoka, M.; Okazaki, K. Magnetic resonance cholangiopancreatography findings in early chronic pancreatitis diagnosed according to the Japanese Diagnostic Criteria. Pancreatology 2020, 20, 596-601. [CrossRef] [PubMed]

42. Gardner, T.B.; Gordon, S.R. Interobserver agreement for pancreatic endoscopic ultrasonography determined by same day back-to-back examinations. J. Clin. Gastroenterol. 2011, 45, 542-545. [CrossRef] [PubMed]

43. Stevens, T.; Lopez, R.; Adler, D.G.; Al-Haddad, M.A.; Conway, J.; Dewitt, J.M.; Forsmark, C.E.; Kahaleh, M.; Lee, L.S.; Levy, M.J.; et al. Multicenter comparison of the interobserver agreement of standard EUS scoring and Rosemont classification scoring for diagnosis of chronic pancreatitis. Gastrointest. Endosc. 2010, 71, 519-526. [CrossRef] [PubMed]

44. Koh, C.J.; Lakhtakia, S.; Kida, M.; Lesmana, C.R.A.; Ang, T.L.; Vu, C.K.F.; Aye, T.T.; Park, S.H.; Almadi, M.A.; Chong, C.C.; et al. Defining the endoscopic ultrasound features of chronic pancreatitis in Asians: A multicenter validation study. Endoscopy 2020. [CrossRef] [PubMed]

45. Costache, M.I.; Dumitrescu, D.; Saftoiu, A. Technique of qualitative and semiquantitative EUS elastography in pancreatic examination. Endosc. Ultrasound 2017, 6, S111-S114. [CrossRef] 
46. Janssen, J.; Papavassiliou, I. Effect of aging and diffuse chronic pancreatitis on pancreas elasticity evaluated using semiquantitative EUS elastography. Ultraschall Med. 2014, 35, 253-258. [CrossRef]

47. Dominguez-Munoz, J.E.; Iglesias-Garcia, J.; Castineira Alvarino, M.; Luaces Regueira, M.; Larino-Noia, J. EUS elastography to predict pancreatic exocrine insufficiency in patients with chronic pancreatitis. Gastrointest. Endosc. 2015, 81, 136-142. [CrossRef]

48. Dominguez-Munoz, J.E. Predicting Pancreatic Exocrine Insufficiency with EUS Elastography. Gastroenterol. Hepatol. 2016, 12, 511-512.

49. Kim, S.Y.; Cho, J.H.; Kim, Y.J.; Kim, E.J.; Park, J.Y.; Jeon, T.J.; Kim, Y.S. Diagnostic efficacy of quantitative endoscopic ultrasound elastography for differentiating pancreatic disease. J. Gastroenterol. Hepatol. 2017, 32, 1115-1122. [CrossRef]

50. Kuwahara, T.; Hirooka, Y.; Kawashima, H.; Ohno, E.; Ishikawa, T.; Kawai, M.; Suhara, H.; Takeyama, T.; Hashizume, K.; Koya, T.; et al. Quantitative diagnosis of chronic pancreatitis using EUS elastography. J. Gastroenterol. 2017, 52, 868-874. [CrossRef]

51. Yashima, Y.; Sasahira, N.; Isayama, H.; Kogure, H.; Ikeda, H.; Hirano, K.; Mizuno, S.; Yagioka, H.; Kawakubo, K.; Sasaki, T.; et al. Acoustic radiation force impulse elastography for noninvasive assessment of chronic pancreatitis. J. Gastroenterol. 2012, 47, 427-432. [CrossRef] [PubMed]

52. Goertz, R.S.; Schuderer, J.; Strobel, D.; Pfeifer, L.; Neurath, M.F.; Wildner, D. Acoustic radiation force impulse shear wave elastography (ARFI) of acute and chronic pancreatitis and pancreatic tumor. Eur. J. Radiol. 2016, 85, 2211-2216. [CrossRef] [PubMed]

53. Yamashita, Y.; Tanioka, K.; Kawaji, Y.; Tamura, T.; Nuta, J.; Hatamaru, K.; Itonaga, M.; Yoshida, T.; Ida, Y.; Maekita, T.; et al. Utility of Elastography with Endoscopic Ultrasonography Shear-Wave Measurement for Diagnosing Chronic Pancreatitis. Gut Liver 2019. [CrossRef] [PubMed]

54. Tirkes, T.; Yadav, D.; Conwell, D.L.; Territo, P.R.; Zhao, X.; Venkatesh, S.K.; Kolipaka, A.; Li, L.; Pisegna, J.R.; Pandol, S.J.; et al. Magnetic resonance imaging as a non-invasive method for the assessment of pancreatic fibrosis (MINIMAP): A comprehensive study design from the consortium for the study of chronic pancreatitis, diabetes, and pancreatic cancer. Abdom. Radiol. 2019, 44, 2809-2821. [CrossRef]

55. Zhang, J.; Zhu, L.; Yao, L.; Ding, X.; Chen, D.; Wu, H.; Lu, Z.; Zhou, W.; Zhang, L.; An, P.; et al. Deep learning-based pancreas segmentation and station recognition system in EUS: Development and validation of a useful training tool (with video). Gastrointest. Endosc. 2020, 92, 874-885. [CrossRef] [PubMed]

56. Kuwahara, T.; Hara, K.; Mizuno, N.; Haba, S.; Okuno, N.; Koda, H.; Miyano, A.; Fumihara, D. Current status of artificial intelligence analysis for endoscopic ultrasonography. Dig. Endosc. 2020. [CrossRef] [PubMed]

Publisher's Note: MDPI stays neutral with regard to jurisdictional claims in published maps and institutional affiliations.

(C) 2020 by the authors. Licensee MDPI, Basel, Switzerland. This article is an open access article distributed under the terms and conditions of the Creative Commons Attribution (CC BY) license (http://creativecommons.org/licenses/by/4.0/). 